\title{
PERSONAL GROWTH AND COVID-19 DISTRESS
}

\author{
Madrudin Magomed-Eminov, Ekaterina Karacheva, Olga Kvasova, \\ Olga Magomed-Eminova, Ivan Prihod'ko, \& Olga Savina \\ Psychological Helping and resocialization Department, Moscow State University (Russian Federation)
}

\begin{abstract}
Various psychological reactions, found to traumatic distress, are widely known in psychological literature. Based on 30-years theoretical and empirical studies of extreme human experience, we suggested unconventional approach to differentiation of psychological reactions and human behavior in various extreme events into three groups:1) distress, disorganization, disorders, traumatization; 2) adaptation, hardiness, resilience; 3) personal growth, transgression (Magomed-Eminov M., 1998, 2007). The proposed research is devoted to the positive psychological consequences of COVID-19 disease. Our aim was to study the positive psychological influence of COVID-19 disease for lifestyle, behavior, communication, life relationships, and well-being of people, who were ill. We suggested and checked the hypothesis, that objectively serious COVID-19 disease, carrying uncertainty, confusion, horror, for many people discover also a heroism, pride, the experience of success because of coping with disease. We collected the narratives of people, who got COVID-19, and conducted content analysis. Our study showed that after being ill COVID-19 interviewed people discovered new meanings of existence, despite the loss of loved ones, socio-economic difficulties and other hardships of COVID- 19 pandemics. We conclude that COVID-19 disease as extreme situation not only becomes a test, but can also open up new perspectives, value of other people and of life in general.
\end{abstract}

Keywords: Peritraumatic COVID-19 distress, posttraumatic growth, resilience, meaning mediation, cultural-historical activity approach, personality work.

\section{Introduction}

In a stressful time, rocked by the Covid-19, this study addresses a worldwide phenomenon not only from catastrophic point of view but also from perspective of positive effects of Covid-19. Authors mainly refer to the negative side of psychological problems: traumatic stress, fear, anxiety, panic, potentially destructive maladaptive defensive responses, such as increased stigmatization and xenophobia, as well as mass panic and protest behavior (Taylor, 2019). They tend to stress health problems, depressive symptoms, insomnia, denial, anger, suicides, negative psychosocial consequences of the outbreak among affected people and the general population (Bo et al, 2020; Sher, 2020; Minihan, 2020). Special attention attracts a number of studies of positive coping strategies and resilience, social support, involvement in educational and creative process considered important in the era of Covid-19. That act as a way of positive human response to misfortune, suffering, pain, threat, which need to cultivate behavioral activation, acceptance, loving-kindness practice, aimed at reducing stress and promoting resilience and recovery (Chew et al., 2020; Polizzi et al, 2020; Prime et al. 2020).

In accordance with our cultural-historical activity approach, we interpret the COVID-19 pandemic as extreme situation (Magomed-Eminov, 1997, 1998, 2007, 2020), specifying it on basis of the triad "suffering - resilience - growth". In terms of adaptation, this triad takes the following forms: "maladaptation - adaptation - development". The adaptive role of positive emotions and their constructive role in coping with distress Bonnano demonstrated in grief studies (Bonanno et al., 2003; Keltner, Bonanno, 1997). The phenomenon of traumatic growth, including post-traumatic growth (R. G. Tedeschi and L. G. Calhoun, 1996; Garcia et al, 2017; Oginska-Bulik, N., 2016) leading to cognitive reconstruction and adaptation to the new reality. That means traumatic adaptation, resilience is not, purely restorative work, and appears as a transcendent, transgressive personality work. 


\section{Design}

Written narratives of respondents from Russia' were collected in online survey during Pandemic - March-October 2021. 434 respondents (average age - 23.5) were asked to report their gender, age, and whether they were ill or not (women $-81 \%$, men $-19 \%$ ), Most of the respondents were senior students of the university. Respondents experienced contracting COVID-19 - 26\% of the sample, non-sick- $74 \%$, $52 \%$ - had family members with COVID- $19,48 \%$ had none of mentioned.

\section{Methods}

Peritraumatic Distress Index (CPDI) (Feng, 2020) the Posttraumatic Growth Inventory (Tedeschi, 1996), Modification of Method of motivational induction (MMI) - 12 incomplete sentences (Nuttin, 1986, Magomed-Eminov, 1997). Method of expert evaluation of narratives and incomplete sentences. Correlation analysis using the TTEST and Pearson criteria.

\section{Results}

In our research we got the following indicators of CPDI and PTG (Table 1.)

Table 1. Comparative analysis of indicators of CPDI and PTG in individuals who experienced contracting COVID-19 and did not experience).

\begin{tabular}{|c|c|c|c|c|}
\hline Variable & $(\mathrm{n}=414)$ & $\begin{array}{l}\text { Experienced contracting } \\
\text { COVID-19 }(\mathrm{n} 1=108)\end{array}$ & $\begin{array}{l}\text { No experience } \\
(\mathrm{n} 2=306)\end{array}$ & $\begin{array}{l}\text { TTEST } \\
\mathrm{P}<.05\end{array}$ \\
\hline $\begin{array}{c}\text { CDPI } \\
\text { M(SD) }\end{array}$ & $25,20(13,93)$ & $27,90(15,02)$ & $24,17(13,41)$ & $0,02 *$ \\
\hline $\begin{array}{c}\text { PTG M } \\
(\text { SD })\end{array}$ & $43,86(24,28)$ & $43,98(22,33)$ & $43,81(24,99)$ & 0,95 \\
\hline
\end{tabular}

CPDI in those who experienced contracting COVID-19 is significantly higher $(\mathrm{p}=0.02)$, than in those subjects who did not experienced contracting. The results of the correlation analysis of the by groups according to the TTEST showed statistically significant differences $(\mathrm{p}=0.02)$. PTG has approximately equal indicators in the group of patients with COVID-19 and non-patients (without COVID-19 contamination). The analysis of the correlation between CPDI and PTG shows a significant relationship (Pearson's $\mathrm{r}=0.23, \mathrm{p}<0.01$ ) between these indicators only in the group of respondents who had experienced COVID-19. The correlation between these indicators in the group of non-ill patients is insignificant (Pearson's r=0.04).

\section{Discussion}

The data show that the very fact of contamination with Covid-19 is distressing (CPD significance level). This data is consistent with a variety of relevant studies (Bo et al, 2020; Brooks, 2000; Minihan, 2020; Sher, 2020). Comparing these data with the differences in PTG, we do not find significant differences. However, if we correlate with that data the relationship found between the CPD index and PTG, the presence of significant correlation between CPDI and contamination could suggest that more severe distress is associated with higher PTG. However, we believe, based on a qualitative analysis of additional data (narratives and incomplete sentences), that those who have a higher level of PTG and the CPDI have qualitative differences in the existential evaluation of their life situation and personal meaning of their experience (Magomed-Eminov, 1997). The narratives were divided into 3 groups from the point of view of the personal working model cultural-historical activity theory: a) suffering, b) adaptation, coping, resilience, c) personal development. We looked at various types of individual experience, including traditionally studied negative distressing experiences, and also from the point of view of action theory and the specifics of the life tasks people solve, personal meaning of the most specific situation in their lives. The statements that attributed to suffering, feeling powerless to change anything (10\% of categories) have following features: "I absolutely don't know how to force myself to increase my activity and interest in what is happening'. The second category - attributed to adaptation actions (75\%), ("I find it very difficult to immediately switch to online training. You have to force yourself to focus on lectures, to be fully involved in work"). The third group concerns personal growth, intrinsic motivation (15\%). The statements demonstrate efforts for self-development ("In the absence of control from the coach, I am 
guided by my own internal motivation and can give more"; "Now I can devote more time to self-development: reading books, studying interesting topics, deepening into the study of languages").

Content analysis of incomplete sentences demonstrates qualitative difference between the statements of sick and non-sick respondents in terms of meaning orientation. The completion of the phrase "I want..." showed: an equal percentage of statements focused on negation, rejection and also on "desire for peace" (19\%), those who were ill had more discourses about development, activity, and prospects $(52 \%)$, compared to those who were not ill (45\%). The statements classified as neutral aimed at preserving and restoring what was lost: $29 \%$ of the respondents who were ill and $35 \%$ of the respondents who were not ill. Noteworthy are the narratives of those who have been contracted COVID-19, which indicate the desire for personal growth: to learn to live in harmony with oneself and the world, to learn more and successfully cope with life; to realize oneself in future profession; to become stronger, kinder and better. Non-ill people have typical narratives: to end the pandemic, to have a stable job, to make life as it was before the restrictions and Covid-19.

\section{Conclusion}

The data demonstrate that PD is stronger in those who experienced COVID-19 contamination, which is evident from data available (Bo et al, 2020; Sher, 2020). Though there are no significant differences in PTG in people who experienced COVID-19 or not. PTG was higher in respondents with high PDI. We suggest that the significance of existential meaning of situation and solution of life tasks (beyond the ordinary experience) may result in personal growth caused by traumatic experience. The experience a person extracts from traumatic situation is mediated by personal meaning. PG is associated not only with personal proactivity, but also with solution of meaning tasks. Respondents in a pandemic situation tend to increase their self-worth, resilience and self-esteem can manage difficulties and feel stronger. In extreme situation of COVID-19 pandemic, people learned about new opportunities in their own lives; discovered new paths, developed new interests, and believed they were ready to change things, beliefs and relations. Newly evaluated coping abilities and resources can become the basis for a new life path choice. Resilience here means that a person experiences suffering, not allowing himself to take the position of victim, martyr. The COVID-19 disease imposes demands on a person that are not comparable with ordinary experiences, a person has to turn to inner resources - to conduct "internal work", support others, take care, which helps to maintain balance in distress. Life's disasters cause not only negative reactions, but also positive transformations of suffering, negativity into growth, development, and courage in personality meaning work, in which the meanings of being, life are considered in relation to the meaning of non-existence, the meaning of death.

\section{References}

Brooks S. K, Webster R. K., Smith L. E, Woodland., Wessely S., Greenberg N., Rubin G. J. (2020) The psychological impact of quarantine and how to reduce it: rapid review of the evidence.- Rapid Review. www.thelancet.com Vol. 395 March 14, 2020

Magomed-Eminov, M.S. (1997). Post-traumatic stress disorders as a loss of meaning of life // States of mind / D. Halpern \& A. Voiskunsky. - Oxford University Press. 238-250.

Magomed-Eminov, M.Sh (2006). Extreme psychology. Moscow: PARF

Magomed-Eminov, M.Sh. et al. (2020) Cultural-historical Activity Psychology in Extreme Situation: The Pandemic Challenge / Discussion. // Chelovec Vol. 31, № 4. 7-40.

Magomed-Eminov, M.Sh.(1998). Personality transformation. Moscow. Psychoanalytic association.

Magomed-Eminov, M.Sh.(2007). Positive human psychology. Moscow: PARF.

Minihan, E., Gavin, B., Kelly, B., \& McNicholas, F. (2020) Covid-19, Mental Health and Psychological First Aid. Irish Journal of Psychological Medicine, 1-12 doi:10.1017/ipm.2020.41

Ng, S. M., \& Lee, T. M. C. (2019) The mediating role of hardiness in the relationship between perceived loneliness and depressive symptoms among older. Aging \& Mental Health, 24(5), 805-810.

Polizzi, C., Lynn, S.J., Perry, A. (2020) Stress and Coping in the Time of COVID-19: Pathways to Resilience and Recovery. Clinical Neuropsychiatry, 17 (2), 59-62.24.

Prime, H., Wade, M., \& Browne, D. T. (2020) Risk and resilience in family well-being during the COVID-19 pandemic. American Psychologist, 75(5), 631-643. doi: 10.1037/amp0000660

Sher L. (2020) Are COVID-19 survivors at increased risk for suicide? Acta Neuropsychiatrica 1-1. doi: $10.1017 /$

Taylor, S. (2019) The Psychology of Pandemics: Preparing for the Next Global Outbreak of Infectious Disease. Cambridge Scholars Publishing, Cambridge. 